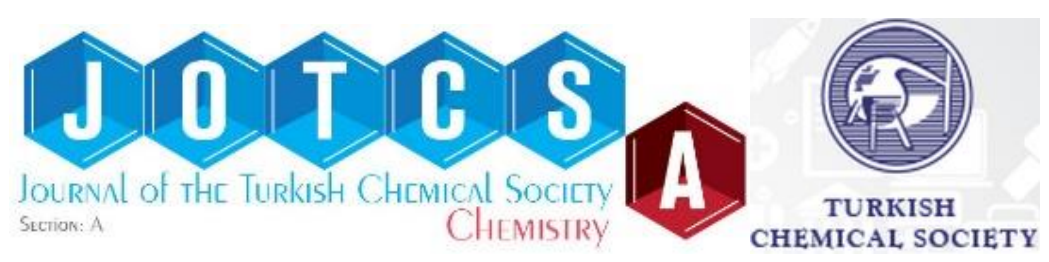

\title{
Synthesis, Characterisation and DFT Calculations of Azo-Imine Dyes
}

\author{
Sevil Özkınalı*, Muhammet Serdar Çavuş², Büşra Sakin \\ ${ }^{1}$ Hitit University, Faculty of Science and Literature, Department of Chemistry, 19040, Çorum, Turkey \\ ${ }^{2}$ Kastamonu University, Faculty of Engineering and Architecture, Biomedical Engineering \\ Department, 37100, Kastamonu, Turkey
}

\begin{abstract}
In this study, azo dyes containing an imine group were synthesised by coupling $p$ hydroxybenzylidene aniline with the diazonium salts of $p$-toluidine, 4 -aminophenol, aniline, $p$ chloroaniline, $p$-fluoroaniline and $p$-nitroaniline. The compounds were characterised by melting point, elemental, UV-Vis and IR analyses as well as ${ }^{1} \mathrm{H}-\mathrm{NMR}$ and ${ }^{13} \mathrm{C}-\mathrm{NMR}$ spectroscopies. Moreover, the experimental data were supplemented with density functional theory (DFT) calculations. The experimental data on FT-IR and UV-Vis spectra of the compounds were compared with theoretical results. The DFT calculations were performed to obtain the ground state geometries of the compounds using the B3LYP hybrid functional level with $6-311++g(2 d, 2 p)$ basis set. Frontier molecular orbital energies, band gap energies and some chemical reactivity parameters, such as chemical hardness and electronegativity, were calculated and compared with experimental values. A significant correlation was observed between the dipole moment and polarities of the solvents and the absorption wavelength of the compounds.
\end{abstract}

Keywords: Azo-imine, Azo-Azomethine, Schiff Bases, DFT, Spectroscopy

Submitted: October 24, 2017. Accepted: November 24, 2017.

Cite this: Özkınalı S, Çavuş M, Sakin B. Synthesis, Characterisation and DFT Calculations of AzoImine Dyes. JOTCSA. 2018;5(1):159-76.

DOI: http://dx.doi.org/10.18596/jotcsa.346278

*Corresponding Author: E-mail Address: sevilozkinali@hitit.edu.tr; T: 03642277000-1636 F: 03642277005 


\section{INTRODUCTION}

Azo dyes have been widely used in various areas, such as textile dyes (1-2), printing systems (2), photoelectronics (3), coloring fibres (4) and optical storage technology. They are also commonly utilised in many biological reactions $(5,6)$ and in analytical chemistry (7-8). Schiff bases are also an important class of organic compounds that exhibit a broad range of biological activities, including antibacterial (9), antifungal (9), antiproliferative (8), anti-inflammatory (4), antimalarial (8), antipyretic (8) and antiviral (5) properties $(6,10)$. Azo dyes and related Schiff bases containing both imine $(-\mathrm{HC}=\mathrm{N}-)$ and azo $(-\mathrm{N}=\mathrm{N}-)$ groups have received much attention in both fundamental and applied research areas. Azo-azomethine dyes containing hydroxyl groups are of particular interest because of the proton tautomerism that exists between the enol-imine and keto-enamine forms $(11-14)$.

Because of the proton-transfer ability of azo-azomethine dyes, they play an important role in many scientific fields; in addition, their tautomers exhibit different optical behaviours and possess different electronic absorption spectra and dyeing properties $(1,4,5)$. The extent to which a tautomer is favoured under certain conditions can play a significant role in terms of its structural and optical behaviours in different medium $(6,15)$. Inter- and intramolecular proton transfer from the phenolic oxygen to the imine nitrogen alters photophysical properties, such as electronic structure and ground- and excited-state dipole moments (5-6). In addition to these solvent effects, substitutions are also important in understanding many chemical and physical behaviours, such as hydrogen bonding and tautomerism of Schiff bases in solutions $(5,6)$. In this study, we examine the relationship between the structural and spectroscopic behaviours of azo dyes containing Schiff bases using density functional theory (DFT) analyses and estimation of singlet ground- and excited-state dipole moments (6).

The literature contains many reports on the successful application of DFT to azo dyes (16-23). In this study, a series of azo dyes containing an imine group were synthesised and characterised using both spectroscopy and Kohn-Sham DFT (24) method. The molecular structures and FT-IR and UVVis spectra of the azo-imine dyes synthesised in this study were obtained using the B3LYP method with $6-311++g(2 d, 2 p)$ basis set. Solvent effects on the absorbance characteristics of the dyes were theoretically studied in solvents of different polarities, such as dichloromethane (DCM), dimethylformamide (DMF) and ethanol (EtOH). 


\section{EXPERIMENTAL PROCESS}

All reagents and solvents for synthesis and analysis were purchased from Merck (Germany) and Sigma-Aldrich (US) and were used without further purification. $p$-Hydroxybenzylidene aniline were synthesised and purified according to methods used in previous studies $(11,25-27)$. In this study compounds 2, 3 and $\mathbf{6}$ are new compounds and these are given here first time in the literature, also theoretical calculations of all the compounds except $\mathbf{4}$ are studied for the first time. Azo-imine compounds were obtained by coupling $p$-hydroxybenzylidene aniline with the diazonium salts of $p$ toluidine, $p$-hydroxyaniline, $p$-chloroaniline, $p$-fluoroaniline and aniline in a $1: 1$ molar ratio at 0 $5^{\circ} \mathrm{C}$. The crude products were purified by recrystallisation from $\mathrm{EtOH}$-water. Elemental $(\mathrm{C}, \mathrm{H}$ and $\mathrm{N}$ ) analyses were performed using a LECO CHNS-932 elemental analyser (LECO Corporation, US). UV-Vis spectra were obtained using a Genesys 10S UV-VIS spectrophotometer (Thermo Scientific, UK) with a concentration of $5 \times 10^{-5} \mathrm{~mol} / \mathrm{L}$ of dye in various solvents, such as EtOH, DCM, and DMF. Infrared spectra were obtained using a Class 1 Laser product FTIR (Thermo Scientific, US) in the 400-4000 $\mathrm{cm}^{-1}$ range. ${ }^{1} \mathrm{H}-\mathrm{NMR}$ and ${ }^{13} \mathrm{C}$-NMR spectra were obtained using an $\mathrm{AC} 400(400 \mathrm{MHz})$ NMR spectrometer (Bruker, Germany) with deuterated dimethylsulphoxide (d6-DMSO) as a solvent and tetramethylsilane as an internal standard.

\section{General procedure for synthesising azo-imine dyes}

p-Hydroxybenzylidene aniline was synthesised by a condensation reaction between $p$ hydroxybenzaldehyde and aniline at a $1: 1$ molar ratio, as described previously $(6,11,25-27)$, and the reaction mixture was refluxed for $3 \mathrm{~h}$. Azo derivatives were synthesised from the $p$ hydroxybenzylidene aniline by reaction with diazonium salts at $0-5^{\circ} \mathrm{C}$. The general synthetic method is depicted in Figure 1.

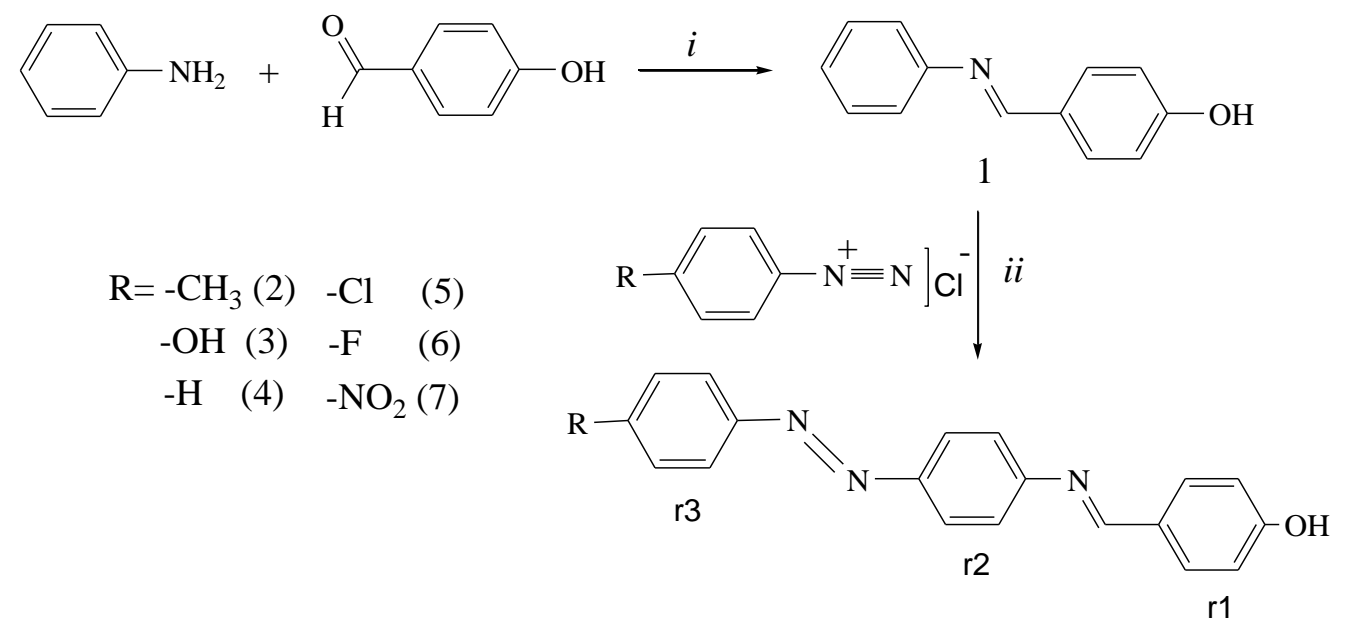

Figure 1. Synthesis of azo-imine compounds (i) $\mathrm{pH}=4-5$, methanol, reflux, $3 \mathrm{~h},(i i) \mathrm{NaNO}_{2}, \mathrm{HCl}$, $0-5^{\circ} \mathrm{C}, \mathrm{r} 1$ : Ring ; r2: Ring 2; r3: Ring 3. 
Özkınalı, Çavuş and Sakin, JOTCSA: 2018; 5(1): 159-178.

RESEARCH ARTICLE

\section{Synthesis of (E)-4-[(phenylimino)methyl]phenol, 1}

Aniline $(0.93 \mathrm{~g} ; 0.01 \mathrm{~mol})$ was added dropwise to a solution of $p$-hydroxybenzaldehyde (1.22 $\mathrm{g}$; $0.01 \mathrm{~mol}$ ) in $35-\mathrm{mL}$ of EtOH. Four to five drops of acetic acid were added to the solution to reach a $\mathrm{pH}$ of 4-5. The reaction mixture was refluxed for $3 \mathrm{~h}$ and left to crystallise at room temperature for a day. The yellow product was collected by filtration, washed with cold water, dried and recrystallised from toluene. Yield: $78 \%$, melting point (m.p.): $185^{\circ} \mathrm{C}-186^{\circ} \mathrm{C}$. IR: $v=3200-2673$ (br, $\mathrm{O}-\mathrm{H}$ ), 3042 (C-H arom.), 1602 (-CH=N-), 1573 (-C=C-), $1283 \mathrm{~cm}^{-1}$ (-C-O). ${ }^{1} \mathrm{H}-\mathrm{NMR}$ (d6-DMSO, ppm): $\delta=10.12(\mathrm{~s}, \mathrm{H} 1), 8.45(\mathrm{~s}, \mathrm{H} 4), 7.76(\mathrm{~d}, \mathrm{~J}=8.8 \mathrm{~Hz}, \mathrm{H} 3), 7.38(\mathrm{t}, \mathrm{J}=5.2 \mathrm{~Hz}, \mathrm{H} 7), 7.21$ (d, $\mathrm{J}=4.0 \mathrm{~Hz}, \mathrm{H} 6), 7.18(\mathrm{~d}, \mathrm{~J}=4.0 \mathrm{~Hz}, \mathrm{H} 5), 6.89(\mathrm{~d}, \mathrm{~J}=8.8 \mathrm{~Hz}, \mathrm{H} 2){ }^{13} \mathrm{C}-\mathrm{NMR}\left(101 \mathrm{MHz}, \mathrm{d}_{6}-\mathrm{DMSO}\right) \delta$ 161.09 (C1), 160.48 (C5), 152.47 (C6), 131.14 (C3), 129.59 (C8), 127.98 (C9), 125.78 (C4), 121.33 (C7), 116.31 (C2). Anal. calcd. (\%) for $\mathrm{C}_{13} \mathrm{H}_{11} \mathrm{NO}$ : C 79.16, H 5.62, N 7.10; found: C 78.85, H 5.47, N 7.07

\section{Synthesis of 4-[[[4-[(4-methylphenyl)azo]phenyl]imino]methyl]-phenol, 2}

Azo-coupled Schiff bases were synthesised using standard coupling methods $(6,8,11)$. $p$-Toluidine $(1 \mathrm{~g} ; 9.33 \mathrm{mmol}$ ) was dissolved in $40-\mathrm{mL}$ water containing concentrated $\mathrm{HCl}$ solution $(2.4 \mathrm{~mL} ; 27.9$ $\mathrm{mmol}$ ) and then diazotised at $0-5^{\circ} \mathrm{C}$ with a solution of $\mathrm{NaNO}_{2}(0.64 \mathrm{~g} ; 9.33 \mathrm{mmol}$ in $4-\mathrm{mL}$ water $)$. The diazonium solution was stirred at $0-5^{\circ} \mathrm{C}$ for $30 \mathrm{~min}$. Following diazotisation, diazonium salt solutions were added dropwise to a solution of $(E)-4-[$ (phenylimino)methyl]phenol $(1,84 \mathrm{~g} ; 9,33$ $\mathrm{mmol}$ ) and $5 \mathrm{~g}$ sodium acetate in $25-\mathrm{mL}$ DMF at $0-5^{\circ} \mathrm{C}$. The resulting solution was stirred for $3 \mathrm{~h}$ at $0-5^{\circ} \mathrm{C}$ and then acidified with $1 \mathrm{M} \mathrm{HCl}$ to precipitate the product. The reddish-brown product was filtered and then washed with cold water before recrystallisation in $\mathrm{EtOH} /$ water. Yield: 68\%, m.p.: 110-111 ${ }^{\circ} \mathrm{C}$. IR: $v=3551-3071$ (br, O-H), 3039 (C-H arom.), 2913,2872 (-C-H, Aliph.), 1602 ($\mathrm{CH}=\mathrm{N}-), 1652,1573$ (-C=C-) , 1514, $1442(-\mathrm{N}=\mathrm{N}-), 1283 \mathrm{~cm}^{-1}(-\mathrm{C}-\mathrm{O}) .{ }^{1} \mathrm{H}-\mathrm{NMR}$ (d6-DMSO, ppm) $\delta=$ $12.01(\mathrm{~s}, \mathrm{H} 1), 7.97(\mathrm{~s}, \mathrm{H} 4), 7.81(\mathrm{~m}, \mathrm{H} 3), 7.68(\mathrm{~m}, \mathrm{H} 8), 7.43(\mathrm{~m}, \mathrm{H} 6), 7.37$ (m, H5), 7.08 (m, H9), 6.67 (m, H2), 1.91 (s, H10) ${ }^{13} \mathrm{C}-\mathrm{NMR}$ (101 MHz, d6-DMSO) $\delta 169.08$ (C1), 162.56 (C5), 156.45 (C6), 152.52 (C9), 147.89 (C13), 142.68 (C8), 141.57 (C10), 130.35 (C3), 129.83 (C12), 122.80 (C11), 125.41 (C4), 123.95 (C7), 119.58 (C2), 21.45 (C14). Anal. calcd. (\%) for $\mathrm{C}_{20} \mathrm{H}_{17} \mathrm{~N}_{3} \mathrm{O}: \mathrm{C} 76.17$, H 5.43, N 13.12; found: C 75.74, H 5.28, N 12.65

\section{Synthesis of 4-[[[4-[(4-hydroxyphenyl)azo]phenyl]imino $]$ methyl]-phenol, 3}

This compound was prepared in a manner similar to that described in section 1.1.2. Yield: $81 \%$, m.p. $186-188^{\circ} \mathrm{C}$. IR: $v=3473-3087$ (br, O-H), 3042 (C-H arom.), $1602(-\mathrm{CH}=\mathrm{N}-), 1612,1573$ ($\mathrm{C}=\mathrm{C}-), 1514,1442(-\mathrm{N}=\mathrm{N}-), 1283,1240,1163 \mathrm{~cm}^{-1}$ (-C-O). ${ }^{1} \mathrm{H}-\mathrm{NMR}$ (d6-DMSO, ppm) $\delta=10.13$ (s, $\mathrm{H1}), 8.45(\mathrm{~s}, \mathrm{H} 4), 7.79(\mathrm{~m}, \mathrm{H} 3), 7.76(\mathrm{~m}, \mathrm{H} 8), 7.20(\mathrm{~m}, \mathrm{H} 6), 7.39(\mathrm{~m}, \mathrm{H} 5), 6.90(\mathrm{~m}, \mathrm{H} 9), 6.87$ (m, $\mathrm{H} 2), 10.13$ (s, H10, OH) ${ }^{13} \mathrm{C}-\mathrm{NMR}\left(101 \mathrm{MHz}, \mathrm{d}_{6}-\mathrm{DMSO}\right) \delta 164.12$ (C1, C13), 160.41(C5), 152.29 (C9), 156.30 (C6), 145.59 (C10), 143.89 (C8), 131.05 (C3), 129.44 (C12), 124.81 (C4), 124.78 
Özkınalı, Çavuş and Sakin, JOTCSA: 2018; 5(1): 159-178.

RESEARCH ARTICLE

(C11), 121.34 (C7), 116.37 (C2). Anal. calcd. (\%) for $\mathrm{C}_{20} \mathrm{H}_{17} \mathrm{~N}_{3} \mathrm{O}: \mathrm{C} 71.91, \mathrm{H} 4.76, \mathrm{~N} 13.24$; found: C $71.25, \mathrm{H} 4.58, \mathrm{~N} 13.04$

\section{Synthesis of 4-[[[4-phenylazo]phenyl]imino]methyl]-Phenol, 4}

This compound was prepared in a manner similar to that described above. Yield: 75\%, m.p.: 78$80^{\circ} \mathrm{C}$. IR: $v=3483-3085$ (br, O-H), 3041(C-H arom.), 1602 (-CH=N-), 1595 (-C=C-), 1504, 1478 $(-\mathrm{N}=\mathrm{N}-), 1239,1137 \mathrm{~cm}^{-1}(-\mathrm{C}-\mathrm{O}) .{ }^{1} \mathrm{H}-\mathrm{NMR}\left(\mathrm{d}_{6}-\mathrm{DMSO}, \mathrm{ppm}\right) \delta=6.10(\mathrm{~s}, \mathrm{H} 1), 7.76(\mathrm{~s}, \mathrm{H} 4), 7.69(\mathrm{~m}$, $\mathrm{H3}), 7.49(\mathrm{~m}, \mathrm{H} 8), 7.49(\mathrm{~m}, \mathrm{H} 6), 7.41(\mathrm{~m}, \mathrm{H} 5), 7.38(\mathrm{~m}, \mathrm{H} 9), 6.69(\mathrm{~m}, \mathrm{H} 2), 7.44(\mathrm{~m}, \mathrm{H} 10){ }^{13} \mathrm{C}-$ NMR (101 MHz, d6-DMSO) $\delta 153.34$ (C1,C6), 152.92 (C5, C9), 145.59 (C10), 143.26 (C8), 130.36 (C13), 129.85(C3), 129.65(C12), 125.65 (C4), 122.52 (C11) 122.16 (C7), 113.84(C2) Anal. calcd. (\%) for $\mathrm{C}_{19} \mathrm{H}_{15} \mathrm{~N}_{3} \mathrm{O}$ : C 75.73, H 5.02, N 13.94; found: C 74.48, H 4.92, N 13.17

\section{Synthesis of 4-[[[4-[(4-chlorophenyl)azo]phenyl]imino]methyl]-phenol, 5}

This compound was prepared a in a manner similar to that described above. Yield: 73\%, m.p.: 72$74^{\circ} \mathrm{C}$. IR: $v=3301-2648$ (br, O-H), 3044(C-H arom.), $1602(-\mathrm{CH}=\mathrm{N}-), 1670,1574(-\mathrm{C}=\mathrm{C}-), 1515$, $1443(-\mathrm{N}=\mathrm{N}-), 1285,1164 \mathrm{~cm}^{-1}(-\mathrm{C}-\mathrm{O}), 840(-\mathrm{C}-\mathrm{Cl}) .{ }^{1} \mathrm{H}-\mathrm{NMR}\left(\mathrm{d}_{6}-\mathrm{DMSO}, \mathrm{ppm}\right) \delta=12.58(\mathrm{~s}, \mathrm{H} 1)$, $8.73(\mathrm{~s}, \mathrm{H} 4), 7.75(\mathrm{~m}, \mathrm{H} 3), 7.66(\mathrm{~m}, \mathrm{H} 8), 7.28(\mathrm{~m}, \mathrm{H} 6), 7.44(\mathrm{~m}, \mathrm{H} 5), 7.04(\mathrm{~m}, \mathrm{H} 9), 6.69$ (m, H2). ${ }^{13} \mathrm{C}-\mathrm{NMR}$ (101 MHz, d6-DMSO) $\delta 153.73$ (C1), 153.34 (C5), 152.92 (C6), 152.57 (C9), 151.12 (C13), 143.22 (C10), 131.52 (C8), 129.73 (C12), 128.96 (C3), 125.92, 125.57 (C4), 122.82 (C11), 122.17 (C7), 113.77 (C2). Anal. calcd. (\%) for $\mathrm{C}_{19} \mathrm{H}_{14} \mathrm{ClN}_{3} \mathrm{O}$ : C 67.96, H 4.20, N 12.51; found: C 67.24, $\mathrm{H}$ $4.14, \mathrm{~N} 11.73$

\section{Synthesis of 4-[[[4-[(4-fluorophenyl)azo]phenyl]imino]methyl]-phenol, 6}

This compound was prepared in a manner similar to that described above. Yield: 76\%, m.p.: 71$72{ }^{\circ} \mathrm{C}$. IR: $v=3386-2745(\mathrm{br}, \mathrm{O}-\mathrm{H}), 3042$ (C-H arom.), $1602(-\mathrm{CH}=\mathrm{N}-), 1572$ (-C=C-), 1514, 1443 $(-\mathrm{N}=\mathrm{N}-), 1283,1163 \mathrm{~cm}^{-1}(-\mathrm{C}-\mathrm{O}), 1193(-\mathrm{C}-\mathrm{F}) .{ }^{1} \mathrm{H}-\mathrm{NMR}$ (d6-DMSO, ppm) $\delta=12.45(\mathrm{~s}, \mathrm{H} 1), 8.45$ (s, $\mathrm{H} 4), 7.79(\mathrm{~m}, \mathrm{H} 3), 7.54(\mathrm{~m}, \mathrm{H} 8), 7.24(\mathrm{~m}, \mathrm{H} 6), 7.41(\mathrm{~m}, \mathrm{H} 5), 7.03(\mathrm{~m}, \mathrm{H} 9), 6.87(\mathrm{~m}, \mathrm{H} 2){ }^{13} \mathrm{C}-\mathrm{NMR}$ (101 MHz, d6-DMSO) $\delta 163.75$ (C1), 160.43 (C13), 161.04 (C5), 152.46 (C9), 150.14 (C6), 146.84 (C10), 142.30 (C8), 131.14 (C3), 129.16 (C12), 125.71 (C4), 122.83 (C7), 121.33 (C11), 116.56 (C2), 114.56 (C12). Anal. calcd. (\%) for $\mathrm{C}_{19} \mathrm{H}_{14} \mathrm{FN} \mathrm{N}_{3} \mathrm{O}$ : C 71.46, $\mathrm{H} 4.42, \mathrm{~N} 13.16$; found: C 71.34, $\mathrm{H}$ $4.38, \mathrm{~N} 12.87$

\section{Synthesis of 4-[[[4-[(4-nitrophenyl)azo]phenyl]imino]methyl]-phenol, 7}

This compound was prepared in a manner similar to that described above. Yield: 77\%, m.p.: 128$130^{\circ} \mathrm{C}$. IR: $v=3544-3068$ (br, O-H), 3047 (C-H arom.), 1602 (-CH=N-), 1572 (-C=C-), 1514, 1442 $(-\mathrm{N}=\mathrm{N}-), 1484,1388\left(-\mathrm{NO}_{2}\right), 1283,1163 \mathrm{~cm}^{-1}(-\mathrm{C}-\mathrm{O}) .{ }^{1} \mathrm{H}-\mathrm{NMR}$ (d6-DMSO, ppm) $\delta=13.03(\mathrm{~s}, \mathrm{H} 1)$, $8.29(\mathrm{~s}, \mathrm{H} 4), 7.60(\mathrm{~m}, \mathrm{H} 3), 7.58(\mathrm{~m}, \mathrm{H} 8), 7.47(\mathrm{~m}, \mathrm{H} 6), 7.50(\mathrm{~m}, \mathrm{H} 5), 7.53(\mathrm{~m}, \mathrm{H} 9), 7.34(\mathrm{~m}, \mathrm{H} 2)$ 
${ }^{13} \mathrm{C}-\mathrm{NMR}$ (101 MHz, d6-DMSO) 163.77 (C1), 158.41 (C5), 153.35 (C9), 152.04 (C6), 149.63 (C13), 142.00 (C10), 14167 (C8), 130.16 (C3), 126.39 (C11), 126.19 (C4), 123.95 (C12), 121.73 (C7), 114.25 (C2). Anal. calcd. (\%) for $\mathrm{C}_{19} \mathrm{H}_{14} \mathrm{~N}_{4} \mathrm{O}_{3}$ : C 65.89, $\mathrm{H} \mathrm{4.07,} \mathrm{N} \mathrm{16.18;} \mathrm{found:} \mathrm{C} \mathrm{65.38,} \mathrm{H} \mathrm{3.96,} \mathrm{N}$ 15.64

\section{Computational details}

Quantum chemical calculations of azo dyes containing an imine group were performed by the Gaussian 09 software package (28) using Becke's three-parameter exchange functional (B3) (29) combined with the nonlocal correlation functional of Lee, Yang and Parr (LYP) (30) with 6$311++\mathrm{G}(2 \mathrm{~d}, 2 \mathrm{p})$ basis set. Ground state geometries of the azo-imine dyes in gas and solvent phases were optimised with the same method and basis set without any constraint on the geometry. Vibrational analysis was used to verify whether the optimised structures corresponded to local minima on the potential energy surface. The self-consistent reaction field method and the conductor-polarizable continuum model (31) were used for UV calculations. The vertical excitation energies and oscillator strengths at the optimised ground state equilibrium geometries were calculated for DCM, DMF and EtOH phases using time-dependent DFT computations and the same hybrid functional and basis set, and the UV-Vis absorption properties of the synthesised azo-imine compounds were investigated for these solvents.

The highest occupied molecular orbital (HOMO), lowest unoccupied molecular orbital (LUMO) and electrostatic potential (ESP) surfaces of the optimised forms of the molecules were obtained. Electronegativity $(X)$ and chemical hardness $(\eta)$ were also calculated. The theoretical results proved invaluable in interpreting the experimental IR and UV-Vis spectra of the compounds.

\section{RESULT AND DISCUSSION}

The UV-Vis spectra of the azo-imine compounds were obtained at a concentration of $1 \times 10^{-5} \mathrm{~mol} / \mathrm{L}$ in EtOH, DCM, DMF and pH of 2 and 12 (in DMF). The UV-Vis spectral results of the compounds are depicted in Table 1 . The major absorption peaks with highest extinction coefficients are attributed to $n \rightarrow \Pi^{*}$ and $\mathrm{n} \rightarrow \Pi^{*}$ transitions at 318-389 $\mathrm{nm}$ and 372-521 nm, respectively. A weak $\mathrm{n} \rightarrow \Pi^{*}$ transition was observed as a shoulder peak in the spectra because it overlapped with the strong $\Pi \rightarrow \Pi^{*}$ transition. Figure 2 shows the UV-Vis spectrum of compound $\mathbf{3}$. Increasing the $\mathrm{pH}$ and polarity produced a bathochromic shift. In acidic medium, the absorption bands for all compounds were observed in the visible spectral region of 328-501 nm (Table 1). 
Özkınalı, Çavuş and Sakin, JOTCSA: 2018; 5(1): 159-178.

RESEARCH ARTICLE

Table 1. Experimental and theoretical UV-Vis data of the compounds 2-7.

\begin{tabular}{|c|c|c|c|c|c|c|c|c|c|c|c|c|c|}
\hline \multirow[b]{2}{*}{ Comp. } & \multirow{2}{*}{$\begin{array}{c}\lambda \text { max. } \\
\text { EtOH } \\
(\mathbf{n m})\end{array}$} & \multirow{2}{*}{$\begin{array}{l}\text { Log } \\
\quad \varepsilon\end{array}$} & \multirow{2}{*}{$\begin{array}{l}\lambda \max . \\
\mathrm{CH}_{2} \mathrm{CI}_{2}\end{array}$} & \multirow{2}{*}{$\begin{array}{l}\text { Log } \\
\qquad \varepsilon\end{array}$} & \multirow{2}{*}{$\begin{array}{c}\lambda \max . \\
\text { DMF }\end{array}$} & \multirow{2}{*}{$\begin{array}{l}\text { Log } \\
\qquad \varepsilon\end{array}$} & \multirow{2}{*}{$\begin{array}{c}\lambda \max . \\
\text { DMF } \\
(\mathrm{pH}=2)\end{array}$} & \multirow{2}{*}{$\begin{array}{l}\log \\
\varepsilon\end{array}$} & \multirow{2}{*}{$\begin{array}{c}\lambda \max . \\
\text { DMF } \\
(\mathrm{pH}= \\
12)\end{array}$} & \multirow{2}{*}{$\begin{array}{l}\text { Log } \\
\qquad \varepsilon\end{array}$} & \multicolumn{3}{|c|}{ Theoretical } \\
\hline & & & & & & & & & & & $\mathrm{EtOH}$ & $\mathrm{CH}_{2} \mathrm{Cl}_{2}$ & DMF \\
\hline \multirow{2}{*}{2} & \multirow{2}{*}{379} & \multirow{2}{*}{3,28} & \multirow{2}{*}{365} & \multirow{2}{*}{3,48} & $350^{s}$ & 3,26 & \multirow{2}{*}{501} & \multirow{2}{*}{3.09} & \multirow{2}{*}{352} & \multirow{2}{*}{3,24} & \multirow{2}{*}{425.4} & \multirow{2}{*}{425.8} & \multirow{2}{*}{427.4} \\
\hline & & & & & 391 & 3,31 & & & & & & & \\
\hline \multirow{2}{*}{3} & \multirow{2}{*}{367} & \multirow{2}{*}{3,31} & \multirow{2}{*}{352} & \multirow{2}{*}{3,72} & \multirow{2}{*}{373} & \multirow{2}{*}{3,88} & 347 & 3.84 & 361 & 3,99 & \multirow{2}{*}{430.2} & \multirow{2}{*}{430.9} & \multirow{2}{*}{432.4} \\
\hline & & & & & & & $378^{s}$ & 3.04 & $398^{s}$ & 3,74 & & & \\
\hline & & & & & & & & & 364 & 4,85 & & & \\
\hline 4 & 318 & 3,53 & 329 & & 405 & 3,44 & 390 & 3,26 & 412 & 3,75 & 423.2 & 423.5 & 425.3 \\
\hline & 396 & 3,87 & 372 & 3.82 & & & & & $520^{s}$ & 3.12 & & & \\
\hline 5 & 380 & 336 & 370 & 388 & 374 & 343 & 198 & 300 & 410 & 3.49 & 4310 & 4324 & 4340 \\
\hline 3 & 389 & 3.30 & $3 / 0$ & 3.80 & $3 / 4$ & 3.43 & 490 & 3.09 & 511 & 3.40 & 431.9 & 432.4 & 434.0 \\
\hline & & & & & & & & & 364 & 4,04 & & & \\
\hline 6 & בכנ & $3, / 1$ & 359 & 3,98 & 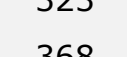 & 3.10 & $3<0$ & 3.00 & $401^{s}$ & 3.85 & 424.2 & 424.8 & 426.3 \\
\hline & $300^{\circ}$ & 3.00 & & & 300 & 3.05 & 300 & 3.00 & 511 & 3.41 & & & \\
\hline 7 & 387 & & 330 & 3.59 & 392 & 3,74 & 384 & 3,47 & 521 & & 397.1 & 394.4 & 398.0 \\
\hline 7 & 301 & 3.01 & 381 & 3.98 & $510^{s}$ & 3.04 & $490^{s}$ & 3.03 & 521 & 3,00 & 501.4 & 498.5 & 504.3 \\
\hline
\end{tabular}

$\lambda$ max. nm, Log $\varepsilon:$ L. $\mathrm{mol}^{-1} \cdot \mathrm{cm}^{-1}$

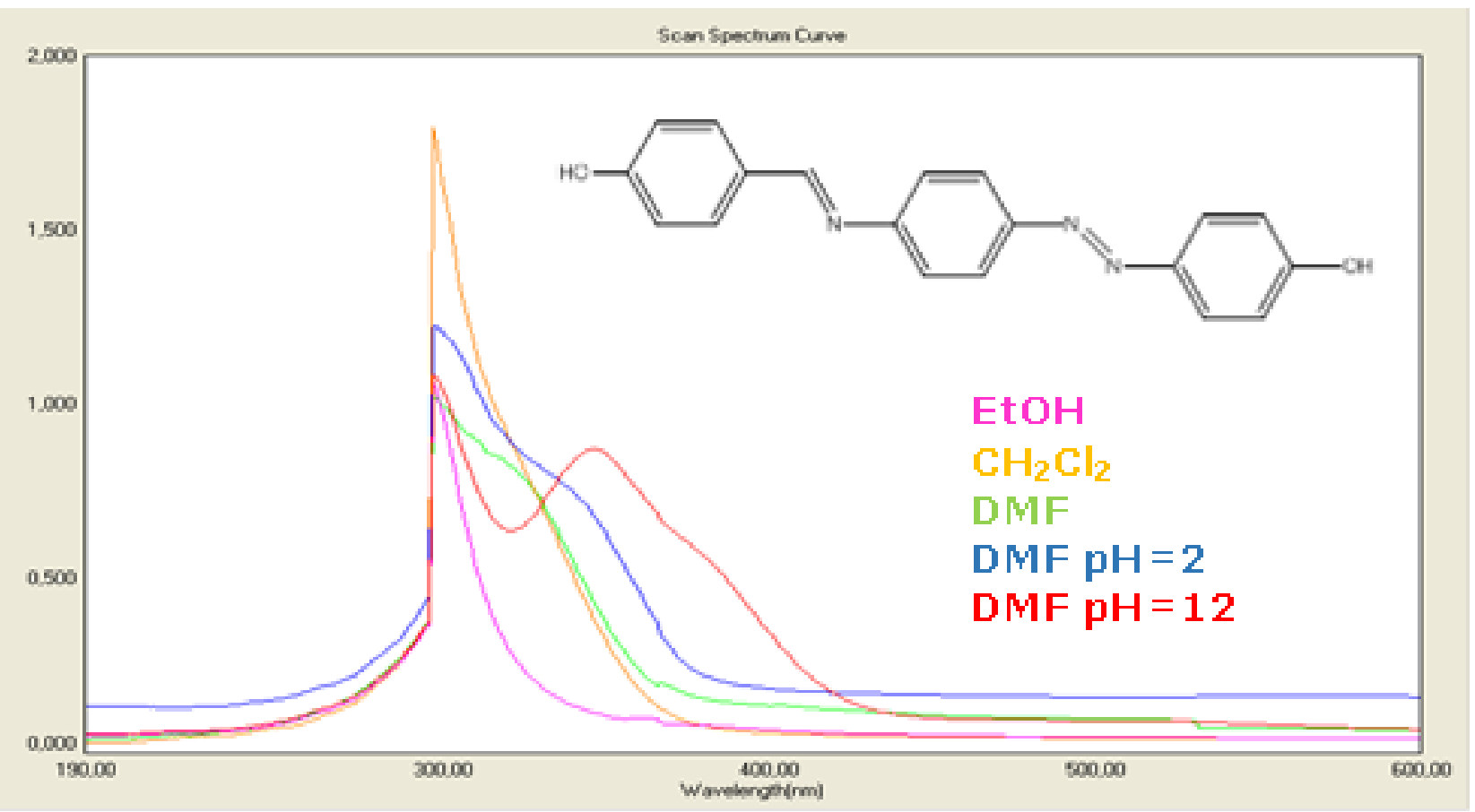

Figure 2. The UV-Vis spectra of 4-[[[4-[(4-hydroxyphenyl)azo]phenyl]imino $]$ methyl]-phenol in $\mathrm{CHCl} 3$, EtOH, DMF, $\mathrm{pH}=2$ (DMF) and $\mathrm{pH}=12$ (DMF). 
Özkınalı, Çavuş and Sakin, JOTCSA: 2018; 5(1): 159-178.

RESEARCH ARTICLE

Consistent with experimental measurements for the compounds, theoretical calculations of their UV-Vis spectra showed that the absorption wavelengths obtained using DMF as a solvent were generally longer than those obtained using other solvents. The absorption wavelengths of compounds 2-7 in DCM and EtOH were found to be at around 425 nm, $430 \mathrm{~nm}, 423 \mathrm{~nm}, 432 \mathrm{~nm}$ and $424 \mathrm{~nm}$, respectively (Table 1), whereas they were $2 \mathrm{~nm}$ higher for the same compounds in DMF. Compound 7, which bore the $\mathrm{NO}_{2}$ substituent, exhibited two large absorption peaks at 398 and $504 \mathrm{~nm}$. Besides, for the compounds 2-6, the effects of $\mathrm{CH}_{3}, \mathrm{OH}, \mathrm{Cl}$ and $\mathrm{F}$ substituents on the absorption wavelengths were determined to be $\lambda_{-\mathrm{Cl}}>\lambda_{-\mathrm{OH}}>\lambda_{-\mathrm{CH}_{3}}>\lambda_{-\mathrm{F}}>\lambda_{-\mathrm{H}}$. An increase in the polarity of the solvent elicited a bathochromic shift in the absorption wavelengths of the compounds, that is, the most polar solvent DMF produced a larger effect than the other solvents. A significant correlation was also observed between the dipole moments of the solvents and the bathochromic shifts they produced ( $\mathrm{m}_{\mathrm{DMF}} \approx 3.86 \mathrm{D}, \mathrm{m}_{\mathrm{EtOH}} \approx 1.69 \mathrm{D}, \mathrm{m}_{\mathrm{DCM}} \approx 1.47 \mathrm{D}$, where $\mathrm{D}$ is Debye).

The IR absorption of the hydroxyl groups of the compounds occurred as a broad peak band in the range of 3551-2672 $\mathrm{cm}^{-1}$ because of intramolecular hydrogen bonding, and the stretching of $\mathrm{HC}=\mathrm{N}$ - was observed at $1602 \mathrm{~cm}^{-1}(5,6)$. In addition, weak peak bands appeared in the ranges 3047-3039 cm $\mathrm{cm}^{-1}$ and 2925-2872 cm $\mathrm{cm}^{-1}$, which can be attributed to aromatic $\mathrm{C}-\mathrm{H}$ and aliphatic =C$\mathrm{H}$ stretching, respectively (Figure 3 and Table 2). The asymmetric and symmetric stretching bands of the azo group $(-\mathrm{N}=\mathrm{N}-)$ were observed at both 1500 and $1450 \mathrm{~cm}^{-1}$. The exact position of these bands varied according to the molecular structure of the compounds, and the strong bands that appeared in the range of $1650-1572 \mathrm{~cm}^{-1}$ of the IR spectra can be attributed to aromatic stretching.

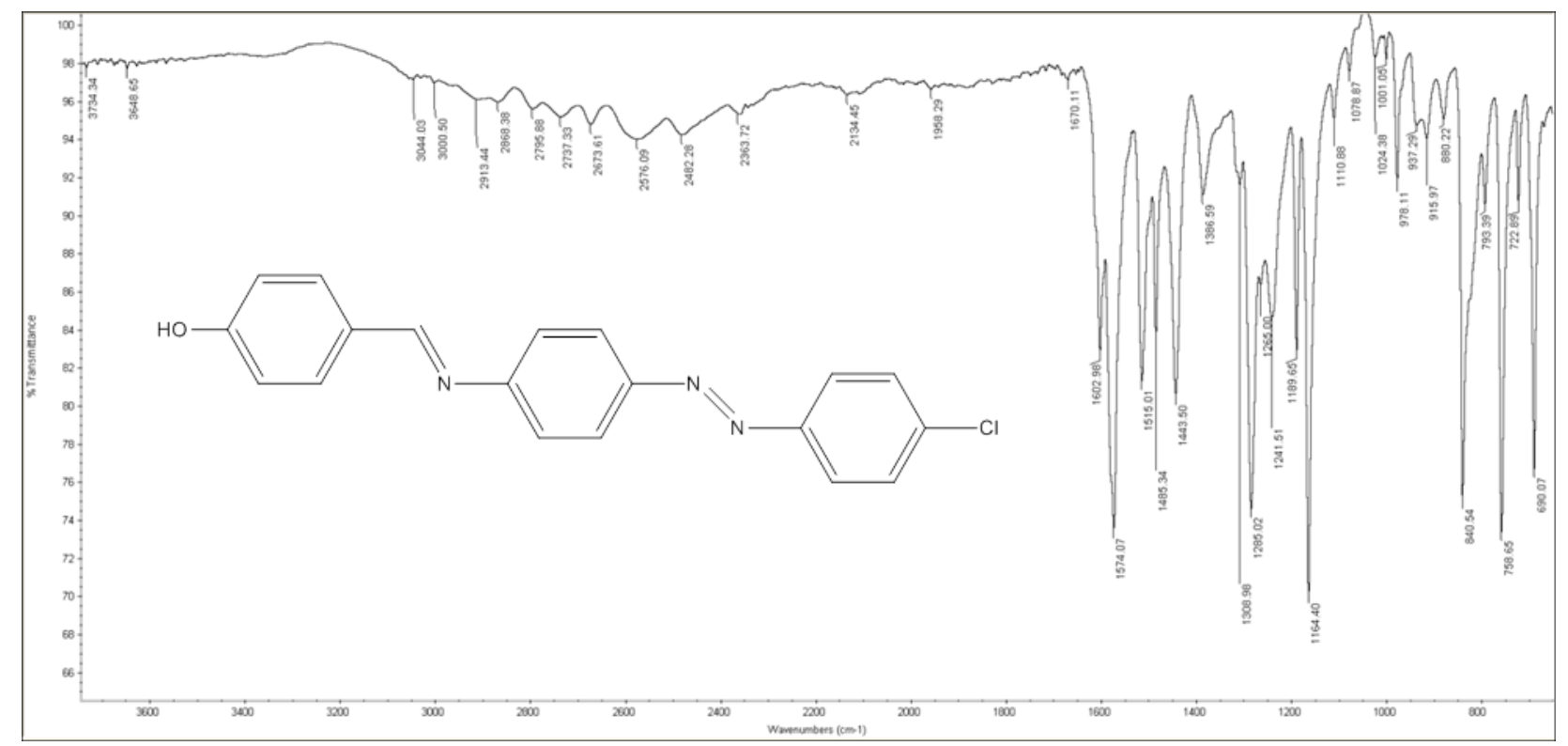

Figure 3. The IR spectrum for 4-[[[4-[(4-chlorophenyl)azo]phenyl]imino $]$ methyl]-Phenol 
Table 2. IR spectral results of compounds 1-7.

\begin{tabular}{|c|c|c|c|c|c|c|c|c|}
\hline Compound & VO-H & $\begin{array}{l}\mathrm{V} \mathrm{C}-\mathrm{H} \\
\text { Arom. }\end{array}$ & $\begin{array}{l}V=C-H \\
\text { Aliph. }\end{array}$ & $v C=N$ & $v c=c$ & $v_{\mathbf{N}}=\mathbf{N}$ & $v_{\text {Ar }-0}$ & $\begin{array}{l}\text { Other functional } \\
\text { groups }\end{array}$ \\
\hline \multirow[t]{2}{*}{1} & $3200-$ & 3042 & 2914 & 1602 & 1573 & - & 1283 & - \\
\hline & 2672 & & 2863 & & & & & \\
\hline \multirow[t]{2}{*}{2} & 3551- & 3039 & 2913 & 1602 & 1652 & 1514 & 1283 & 2913 and \\
\hline & 3071 & & 2854 & & 1573 & 1442 & & $2872\left(\mathrm{CH}_{3}\right)$ \\
\hline \multirow[t]{3}{*}{3} & $3473-$ & 3042 & 2923 & 1602 & 1612 & 1514 & 1283 & - \\
\hline & 3087 & & 2872 & & 1573 & 1442 & 1240 & \\
\hline & & & & & & & 1163 & \\
\hline \multirow[t]{2}{*}{4} & 3483- & 3041 & 2918 & 1602 & 1595 & 1504 & 1239 & - \\
\hline & 3085 & & 2863 & & & 1478 & 1137 & \\
\hline \multirow[t]{2}{*}{5} & 3301- & 3044 & 2913 & 1602 & 1670 & 1515 & 1285 & $840(\mathrm{C}-\mathrm{Cl})$ \\
\hline & 2648 & & 2868 & & 1574 & 1443 & 1164 & \\
\hline \multirow[t]{2}{*}{6} & 3386- & 3042 & 2924 & 1602 & 1573 & 1514 & 1283 & $1193(C-F)$ \\
\hline & 2745 & & 2874 & & & 1443 & 1163 & \\
\hline \multirow[t]{2}{*}{7} & $3544-$ & 3047 & 2925 & 1602 & 1572 & 1514 & 1283 & 1484 and \\
\hline & 3068 & & 2864 & & & 1442 & 1163 & $1388\left(\mathrm{NO}_{2}\right)$ \\
\hline
\end{tabular}

As can be seen in Table 3, the theoretical and experimental IR results were in close agreement. However, because the theoretical calculations were performed for single molecules (i.e. intermolecular interactions were not taken into account), calculated aromatic and aliphatic $=\mathrm{C}-\mathrm{H}$ bond vibrations were found to be higher than experimentally determined values. $-\mathrm{CH}_{3},-\mathrm{OH},-\mathrm{Cl}$ and - $\mathrm{F}$ substituents did not significantly alter the vibration of $\mathrm{O}-\mathrm{H}$, whereas $\mathrm{NO}_{2}$ substitution had a more pronounced effect (Table 3). Substituents appeared to have the most effect on $\mathrm{N}=\mathrm{N}$ vibrations. For example, in unsubstituted compound 4 the $-\mathrm{N}=\mathrm{N}$ - vibration frequency had its highest value (1534 $\mathrm{cm}^{-1}$ ), and the difference in the electronegativity of the substituents had little effect on other oscillation frequencies except for the $-\mathrm{N}=\mathrm{N}$ - bond and aromatic $\mathrm{C}-\mathrm{H}$ vibrations of ring 3 . Both the experimental and theoretical results showed that $\mathrm{C}=\mathrm{N}$ vibrations were particularly unaffected by substituent variation (experimental, $1602 \mathrm{~cm}^{-1}$; theoretical, $1679 \mathrm{~cm}^{-1}$ ). All selected oscillation frequencies are shown in Table 3. 
Özkınalı, Çavuş and Sakin, JOTCSA: 2018; 5(1): 159-178.

RESEARCH ARTICLE

Table 3. Theoretical IR spectral results of the compounds.

\begin{tabular}{|c|c|c|c|c|c|c|c|c|}
\hline Compound & Vo-H & $\begin{array}{l}V \mathrm{C}-\mathrm{H} \\
\text { Arom. }\end{array}$ & $\begin{array}{l}V=C-H \\
\text { Aliph. }\end{array}$ & $v C=N$ & $v c=c$ & $V_{N}=N$ & $V_{\text {Ar-O }}$ & $\begin{array}{c}\text { Other } \\
\text { functional } \\
\text { groups }\end{array}$ \\
\hline \multirow{3}{*}{2} & \multirow{3}{*}{3832} & $3179(r 2)$ & \multirow{3}{*}{3011} & \multirow{3}{*}{1680} & 1646 & \multirow{3}{*}{$\begin{array}{l}1490 \\
1438\end{array}$} & \multirow{3}{*}{1286} & 3109 \\
\hline & & $3160(r 3)$ & & & 1618 & & & 3076 \\
\hline & & $3158(r 1)$ & & & 1548 & & & $3032\left(\mathrm{CH}_{3}\right)$ \\
\hline \multirow{3}{*}{3} & \multirow{3}{*}{$\begin{array}{l}3833(r 3) \\
3831(r 1)\end{array}$} & $3178(r 2)$ & \multirow{3}{*}{3009} & \multirow{3}{*}{1678} & 1642 & \multirow{3}{*}{$\begin{array}{l}1496 \\
1466\end{array}$} & \multirow{3}{*}{$\begin{array}{l}1289(r 1) \\
1281(r 2)\end{array}$} & \multirow{3}{*}{$3833(\mathrm{O}-\mathrm{H})$} \\
\hline & & $3159(r 1)$ & & & 1612 & & & \\
\hline & & $3153(r 3)$ & & & 1527 & & & \\
\hline \multirow{3}{*}{4} & \multirow{3}{*}{3831} & $3199(r 3)$ & \multirow{3}{*}{3010} & \multirow{3}{*}{1679} & 1647 & \multirow{3}{*}{$\begin{array}{l}1534 \\
1445\end{array}$} & \multirow{3}{*}{1290} & \multirow{3}{*}{-} \\
\hline & & $3179(r 2)$ & & & 1612 & & & \\
\hline & & $3176(r 1)$ & & & 1548 & & & \\
\hline \multirow{3}{*}{5} & \multirow{3}{*}{3831} & $\begin{array}{c}3218(r 3- \\
\text { weak) }\end{array}$ & \multirow{3}{*}{3010} & \multirow{3}{*}{1679} & 1647 & \multirow{3}{*}{$\begin{array}{l}1530 \\
1492\end{array}$} & \multirow{3}{*}{1290} & \multirow{3}{*}{$1095(\mathrm{C}-\mathrm{Cl})$} \\
\hline & & $3180(r 2)$ & & & 1612 & & & \\
\hline & & $3160(r 1)$ & & & 1548 & & & \\
\hline \multirow{3}{*}{6} & \multirow{3}{*}{3831} & $\begin{array}{c}3210 \text { (r3- } \\
\text { weak) }\end{array}$ & \multirow{3}{*}{3010} & \multirow{3}{*}{1679} & 1647 & \multirow{3}{*}{$\begin{array}{l}1496 \\
1439\end{array}$} & \multirow{3}{*}{1290} & \multirow{3}{*}{$1238(\mathrm{C}-\mathrm{F})$} \\
\hline & & $3179(r 2)$ & & & 1612 & & & \\
\hline & & $3160(r 1)$ & & & $10<1$ & & & \\
\hline \multirow{3}{*}{7} & & weak $(r 3)$ & & & 1647 & & & \\
\hline & 3830 & $3205(r 2)$ & 3012 & 1679 & 1611 & $10<0$ & 1292 & $1359\left(\mathrm{NO}_{2}\right)$ \\
\hline & & $3160(r 1)$ & & & 1528 & 1400 & & \\
\hline
\end{tabular}

$\mathrm{r} 1$ : ring $1, \mathrm{r} 2$ : ring $2, \mathrm{r} 3$ : ring 3

The ${ }^{1} \mathrm{H}-\mathrm{NMR}$ spectra of the compounds were produced using DMSO- $\mathrm{d}_{6}$, and the signals at $7.81 \mathrm{ppm}$ and $6.67 \mathrm{ppm}$ were assigned to the aromatic protons. The signal stemmed from imine group appeared as a singlet in the range of 8.45 and $7.76 \mathrm{ppm}$. Aromatic protons were observed as doublets and, in a few cases, as overlapping doublets/multiplets. The singlet peak of the $\mathrm{OH}$ group appeared at 13.03 and 10.12 ppm except for that of the $\mathrm{OH}$ group the compound $\mathbf{4}$, which appeared at $6.10 \mathrm{ppm}$. An additional signal at $1.91 \mathrm{ppm}$, which was found in compound 2, was attributed to the $\mathrm{CH}_{3}$ group. Hydroxyl and imine protons were observed as singlet peaks at 13.03 and 8.29 ppm for the $\mathrm{H} 1$ and $\mathrm{H} 4$ protons in the spectrum of compound 7 (Figure 4). The peak at 7.34-7.60 ppm was attributed to signals from aromatic protons (Table 4). Protons $(\mathrm{H} 2-\mathrm{H} 7)$ on the benzene ring adjacent to the nitro group shifted downfield, as expected, due to the unsubstituted benzene protons $(\mathrm{H} 2-\mathrm{H} 7)$ in the compound 7. 


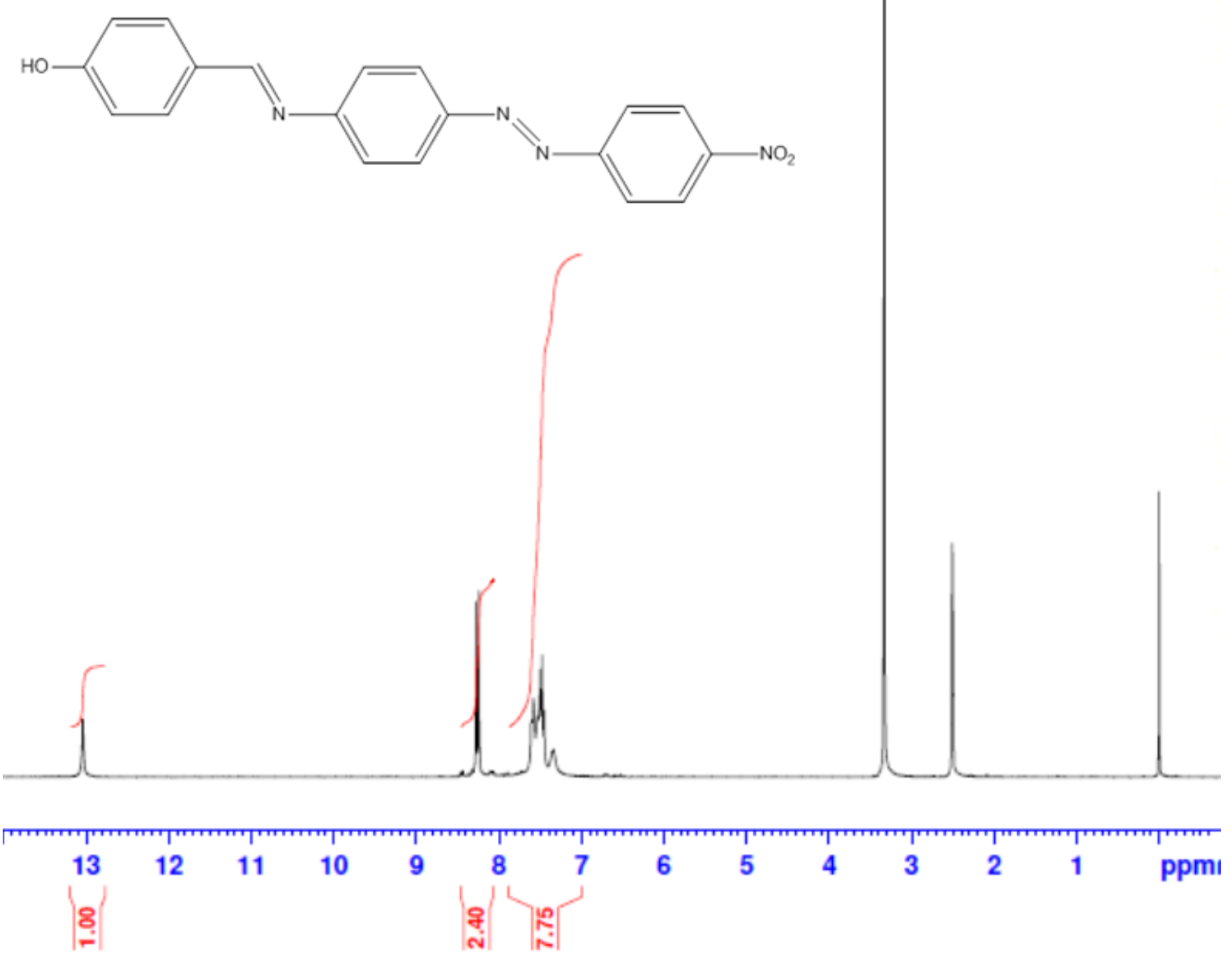

Figure 4. The ${ }^{1} \mathrm{H}-\mathrm{NMR}$ Spectrum of 4-[[[4-[(4-nitrophenyl)azo]phenyl]imino $]$ methyl]-Phenol 
Table 4. ${ }^{1} \mathrm{H}-\mathrm{NMR}$ spectral results of compounds 1-7.

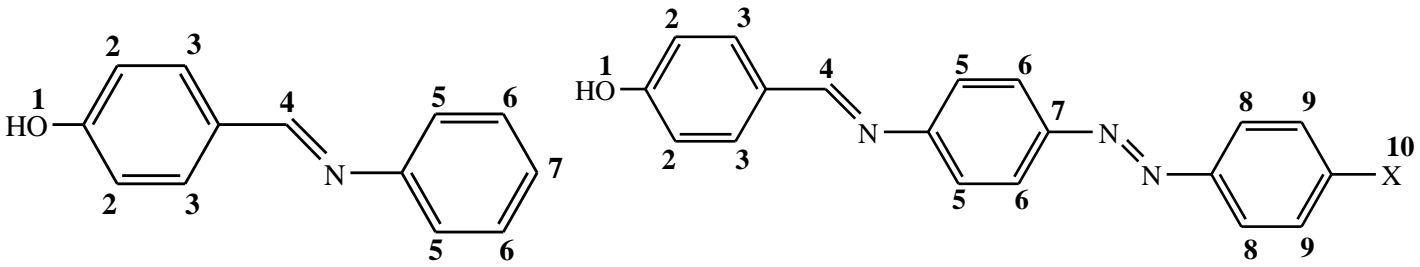

\section{Compound 1}

$\mathbf{X}=\mathrm{CH}_{3}(\mathbf{2}),-\mathrm{OH}(\mathbf{3}),-\mathrm{H}(\mathbf{4}),-\mathrm{Cl}(\mathbf{5}),-\mathrm{F}(\mathbf{6}), \mathrm{NO}_{2}$ (7)

\begin{tabular}{lllllllllll}
\hline & H1 & H2 & H3 & H4 & H5 & H6 & H7 & H8 & H9 & H10 \\
\hline $\mathbf{1}$ & $10.12(\mathrm{~s})$ & $6.89(\mathrm{~d})$ & $7.76(\mathrm{~d})$ & $8.45(\mathrm{~s})$ & $7.18(\mathrm{~d})$ & $7.21(\mathrm{~d})$ & $7.38(\mathrm{t})$ & - & - & - \\
$\mathbf{2}$ & $12.01(\mathrm{~s})$ & $6.67(\mathrm{~m})$ & $7.81(\mathrm{~m})$ & $7.97(\mathrm{~s})$ & $7.37(\mathrm{~m})$ & $7.43(\mathrm{~m})$ & - & $7.68(\mathrm{~m})$ & $7.08(\mathrm{~m})$ & $1.91(\mathrm{~s})$ \\
$\mathbf{3}$ & $10.13(\mathrm{~s})$ & $6.87(\mathrm{~m})$ & $7.79(\mathrm{~m})$ & $8.45(\mathrm{~s})$ & $7.39(\mathrm{~m})$ & $7.20(\mathrm{~m})$ & - & $7.76(\mathrm{~m})$ & $6.90(\mathrm{~m})$ & $10.13(\mathrm{~s})$ \\
$\mathbf{4}$ & $6.10(\mathrm{~s})$ & $6.69(\mathrm{~m})$ & $7.69(\mathrm{~m})$ & $7.76(\mathrm{~s})$ & $7.41(\mathrm{~m})$ & $7.49(\mathrm{~m})$ & - & $7.49(\mathrm{~m})$ & $7.38(\mathrm{~m})$ & $7.44(\mathrm{~m})$ \\
$\mathbf{5}$ & $12.58(\mathrm{~s})$ & $6.69(\mathrm{~m})$ & $7.75(\mathrm{~m})$ & $8.73(\mathrm{~s})$ & $7.44(\mathrm{~m})$ & $7.28(\mathrm{~m})$ & - & $7.66(\mathrm{~m})$ & $7.04(\mathrm{~m})$ & - \\
$\mathbf{6}$ & $12.45(\mathrm{~s})$ & $6.87(\mathrm{~m})$ & $7.79(\mathrm{~m})$ & $8.45(\mathrm{~s})$ & $7.41(\mathrm{~m})$ & $7.24(\mathrm{~m})$ & - & $7.54(\mathrm{~m})$ & $7.03(\mathrm{~m})$ & - \\
$\mathbf{7}$ & $13.03(\mathrm{~s})$ & $7.34(\mathrm{~m})$ & $7.60(\mathrm{~m})$ & $8.29(\mathrm{~s})$ & $7.50(\mathrm{~m})$ & $7.47(\mathrm{~m})$ & - & $7.58(\mathrm{~m})$ & $7.53(\mathrm{~m})$ & - \\
\hline
\end{tabular}


Özkınalı, Çavuş and Sakin, JOTCSA: 2018; 5(1): 159-178.

Theoretical calculations showed that the highest molecular energy among compounds 2-7 was shown by the unsubstituted compound 4 ( $-972.776 \mathrm{au})$ and that there was no relationship between the electronegativity of substituent groups and the molecular energies of the compounds. Compound 5, bearing the $-\mathrm{Cl}$ substituent, had the lowest molecular energy $(-1432.400 \mathrm{au})$. The $\mathrm{NO}_{2}$ substituted compound 7 possessed the lowest HOMO-LUMO energy gap $(\Delta \mathrm{E})$ and the highest electronegativity (4.798 eV) and dipole moment (9.914 D). Therefore, compound 7 exhibited the lowest chemical hardness $(1.517 \mathrm{eV})$ and the highest reactivity. Conversely, unsubstituted compound $\mathbf{4}$ exhibited the highest chemical hardness. Comparison between compounds $\mathbf{4}$ and 2 showed that the methyl substituent decreased the dipole moment of the compound $\mathbf{4}$ from 3.6 to $1.5 \mathrm{D}$.

Table 5. Electronic and chemical parameters calculated by B3lyp/6-311++g(2d,2p)

\begin{tabular}{cccccccc} 
Compound & $\boldsymbol{E}(\mathbf{a u})$ & $\boldsymbol{E}_{\text {homo }}(\mathbf{e V})$ & $\boldsymbol{E}_{\text {lumo }}(\mathbf{e V})$ & $\Delta \boldsymbol{E}$ & $\boldsymbol{\eta}(\mathbf{e V})$ & $\chi(\mathbf{e V})$ & $\boldsymbol{m}(\mathbf{D})$ \\
\hline $\mathbf{2}$ & -1012.105 & -5.862 & -2.455 & 3.406 & 1.703 & 4.158 & 1.501 \\
$\mathbf{3}$ & -1048.026 & -5.765 & -2.417 & 3.348 & 1.674 & 4.091 & 2.469 \\
$\mathbf{4}$ & -972.776 & -5.954 & -2.529 & 3.425 & 1.713 & 4.242 & 3.600 \\
$\mathbf{5}$ & -1432.400 & -6.022 & -2.673 & 3.350 & 1.675 & 4.348 & 5.276 \\
$\mathbf{6}$ & -1072.046 & -5.992 & -2.593 & 3.399 & 1.700 & 4.293 & 4.903 \\
$\mathbf{7}$ & -1177.345 & -6.315 & -3.282 & 3.033 & 1.517 & 4.798 & 9.914
\end{tabular}

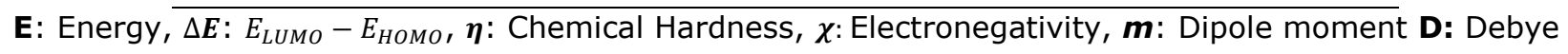

As can be seen from Table 5, there is no obvious relationship between the electronegativity of the substituents and that of the compounds 2-6. However, compound 7, which bore the highest electronegative substituent $\left(\mathrm{NO}_{2}\right)$, also showed the highest electronegative. However, these data still suggest that a substituent's electronegativity is not necessarily the only criterion that determines the molecular electronegativity of the compound. The calculated electronic and chemical values of the compounds are shown in the Table 5. Furthermore, the calculated HOMO-LUMO and ESP maps of the molecules are given in Figure 5. 


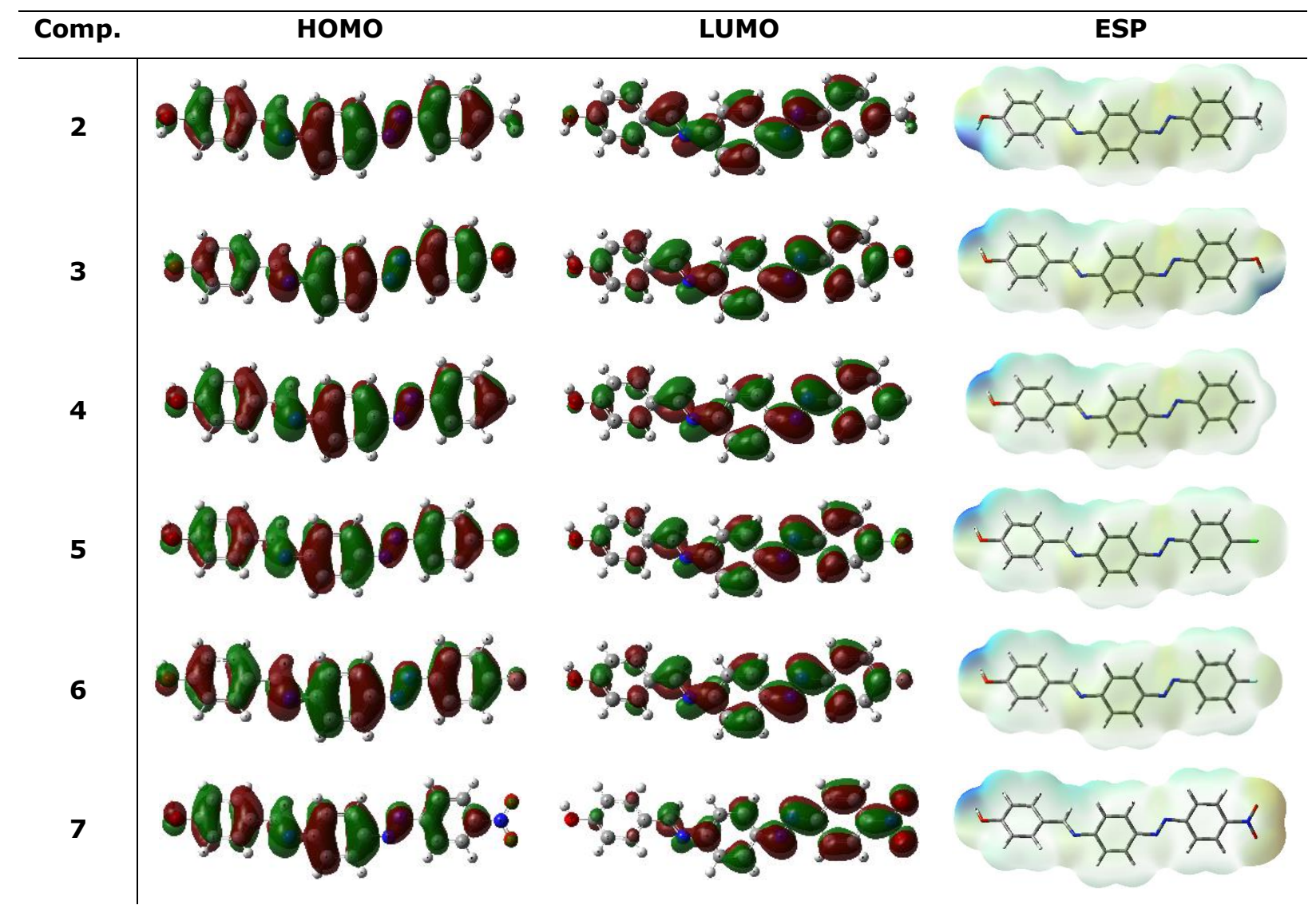

Figure 5. HOMO-LUMO and ESP maps of the compounds.

In ${ }^{13} \mathrm{C}$-NMR spectra, which are shown in Table 6 and Figure 6 , the aromatic and imine carbon atoms appear in the same region of 163.77-121.33 ppm, which is in agreement with values reported in the literature $(5,8,13)$. The $\mathrm{C} 1$ atom conjugated to the $\mathrm{OH}$ group produced a signal downfield from the other carbon atoms, whereas the C5 and C6 atoms were shifted downfield, as expected, due to the nitrogen atom. In the substituted benzene ring, the $\mathrm{C} 13$ carbon atom resonated downfield due to a decrease in electron density resulting from the presence of $-\mathrm{OH},-\mathrm{Cl},-\mathrm{F}$ or $-\mathrm{NO}_{2}$. Conversely, the presence of the electron-donating $-\mathrm{CH}_{3}$ group resulted in upfield shifts in carbon atoms resonances due to an increase in electron density. 
Özkınalı, Çavuş and Sakin, JOTCSA: 2018; 5(1): 159-178.

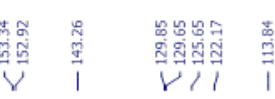
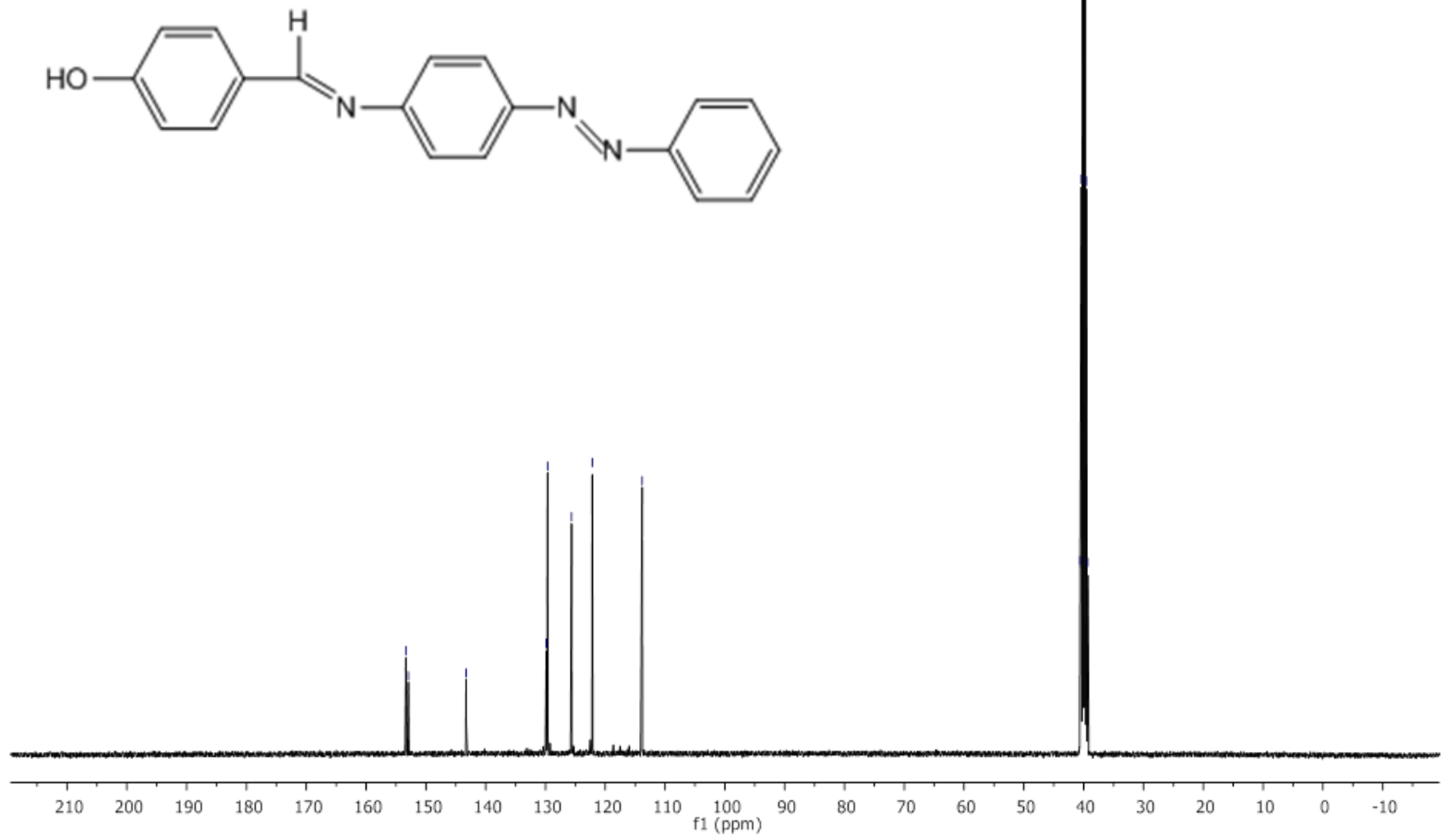

Figure 6. The ${ }^{1} \mathrm{H}-\mathrm{NMR}$ Spectrum of 4-[[[4-[(phenyl)azo $]$ phenyl $]$ imino $]$ methyl]-phenol 
Table 6. ${ }^{13} \mathrm{C}-\mathrm{NMR}$ spectral results of compounds 1-7.
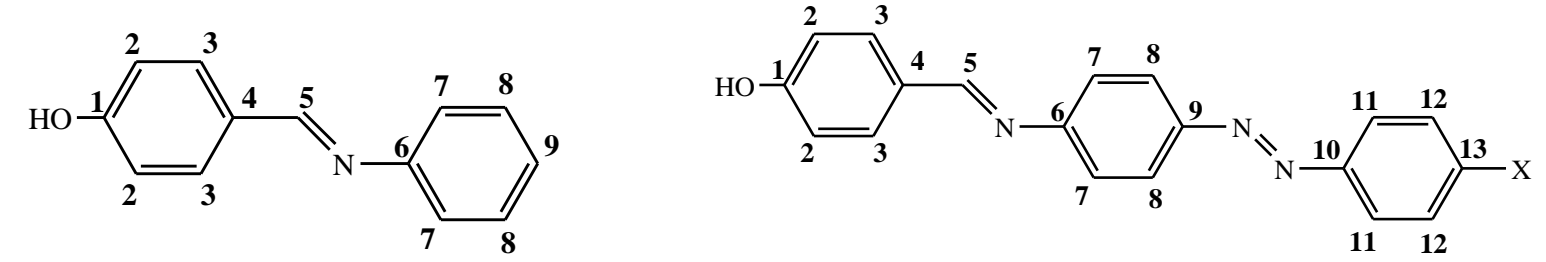

Compound 1

$\mathbf{X}=\mathrm{CH}_{3}(\mathbf{2}),-\mathrm{OH}(\mathbf{3}),-\mathrm{H}(\mathbf{4}),-\mathrm{Cl}(\mathbf{5}),-\mathrm{F}(\mathbf{6}), \mathrm{NO}_{2}(\mathbf{7})$

\begin{tabular}{c|c|c|c|c|c|c|c|c|c|c|c|c|c}
\hline & $\mathbf{C 1}$ & $\mathbf{C 2}$ & $\mathbf{C 3}$ & $\mathbf{C 4}$ & $\mathbf{C 5}$ & $\mathbf{C 6}$ & $\mathbf{C 7}$ & $\mathbf{C 8}$ & $\mathbf{C 9}$ & $\mathbf{C 1 0}$ & $\mathbf{C 1 1}$ & $\mathbf{C 1 2}$ & $\mathbf{C 1 3}$ \\
\hline $\mathbf{1}$ & 161.09 & 116.31 & 131.14 & 125.78 & 160.48 & 152.47 & 121.33 & 129.59 & 127.98 & - & - & - & - \\
\hline $\mathbf{2}$ & 169.08 & 119.58 & 130.35 & 125.41 & 162.56 & 156.45 & 123.95 & 142.68 & 152.52 & 141.57 & 122.80 & 129.83 & 147.89 \\
\hline $\mathbf{3}$ & 164.12 & 116.37 & 131.05 & 124.81 & 160.41 & 156.30 & 121.34 & 143.89 & 152.29 & 145.59 & 124.78 & 129.44 & 164.12 \\
\hline $\mathbf{4}$ & 153.34 & 113.84 & 129.85 & 125.65 & 152.92 & 153.34 & 122.16 & 143.26 & 152.29 & 145.59 & 122.52 & 129.65 & 130.36 \\
\hline $\mathbf{5}$ & 153.73 & 113.77 & 128.96 & 125.57 & 153.34 & 152.92 & 122.17 & 131.52 & 152.57 & 143.22 & 122.82 & 129.73 & 151.12 \\
\hline $\mathbf{6}$ & 163.75 & 116.56 & 131.14 & 125.71 & 161.04 & 150.14 & 122.83 & 142.30 & 152.46 & 146.84 & 121.33 & 114.56 & 160.43 \\
\hline $\mathbf{7}$ & 163.77 & 114.25 & 130.16 & 126.19 & 158.41 & 152.04 & 121.73 & 141.67 & 153.35 & 142.00 & 126.39 & 123.95 & 149.63 \\
\hline
\end{tabular}


Özkınalı, Çavuş and Sakin, JOTCSA: 2018; 5(1): 159-178.

RESEARCH ARTICLE

\section{CONCLUSION}

The azo-imine compounds synthesised in this study were obtained in a high yield and were characterised by UV-Vis, IR, NMR and elemental analyses. Spectroscopic and elemental analyses revealed the expected results. The UV-Vis electronic absorption and IR spectra of the compounds were determined both experimentally and also computationally using DFT. The UV-Vis spectra of the compounds exhibited two absorption bands in the ranges of 318-389 and 372-521 nm, which were assigned to $\pi \rightarrow \pi^{*}$ and $\mathrm{n} \rightarrow \pi^{*}$ transitions, respectively. ${ }^{1} \mathrm{H}$ - and ${ }^{13} \mathrm{C}$ NMR spectroscopy confirmed the presence of the functional groups, particularly the $-\mathrm{N}=\mathrm{N}-$ and $-\mathrm{HC}=\mathrm{N}-$ imine groups, of the compounds.

\section{REFERENCES}

1. Umape P.G, Patil V.S, Padalkar V.S, Phatangare K.R, Gupta V.D, Thate A.B, Sekar N, Synthesis and characterization of novel yellow azo dyes from 2-morpholin-4-yl-1,3-thiazol-(5H)-one and study of their azohydrazone tautomerism. Dyes and Pigments. 2013;99: 291-298.

2. Gür M., Kocaokutgen H., M. Taş, Synthesis, spectral and thermal characterissation of some azo-ester derivatives containing a 4-acryloyloxy group, Dyes and Pigments, 2007, 72, 101-108.

3. Al-Hamdani A.A.S, Balkhi A.M, Falah A, Shaker S.A, Synthesis and investigation of thermal properties of vanadyl complexes with azo-containing Schiff-base dyes, Journal of Saudi Chemical Society, 2016; 20: 487501

4. Bitmez Ş, Sayin K, Avar B, Köse M, Karayıldız A, Kurtoğlu M, Preparation, spectral, X-ray powder diffraction and computational studies and genotoxic properties of new azo-azomethine metal chelates, Journal of Molecular Structure. 2014:1076; 213-226

5. Eren T, Köse M, Kurtoğlu N, Ceyhan G, McKee V, Kurtoğlu M, An azo-azomethine ligand and its copper(II) complex: Synthesis, X-ray crystal structure, spectral, thermal, electrochemical and photoluminescence properties. Inorganica Chimica Acta 2015; 430: 268-279

6. Köse M, Kurtoğlu N, Gümüşsu Ö, Tutak M, McKee V, Karakaş D, Kurtoğlu M, Synthesis, characterization and antimicrobial studies of 2-\{(E)-[(2-hydroxy-5-methylphenyl)imino]methyl $\}-4-[(E)$-phenyldiazenyl] phenol as a novel azo-azomethine dye. Journal of Molecular Structure. 2013; 1053: 89-99

7. Kantar C, Mavi, V, Baltas N, İslamoğlu F, Şaşmaz S, Novel zinc(II)phthalocyanines bearing azo-containing schiff base: Determination of pKa values, absorption, emission, enzyme inhibition and photochemical properties. Journal of Molecular Structure. 2016; 1122: 88-99

8. Purtas F, Sayin K, Ceyhan G, Kose M, Kurtoglu M, New fluorescent azo-Schiff base Cu(II) and Zn(II) metal chelates; spectral, structural, electrochemical, photoluminescence and computational studies. Journal of Molecular Structure. 2017; 1137: 461-475.

9. Alaghaz A.M.A, Zayed M. E, Alharbi S. A, Synthesis, spectral characterization, molecular modeling and antimicrobial studies of tridentate azo-dye Schiff base metal complexes. Journal of Molecular Structure. 2015; 1084: $36-45$

10. Zakerhamidi M.S, Nejati K, Sorkhabi S.G, Saati M, Substituent and solvent effects on the spectroscopic properties and dipole moments of hydroxyl benzaldehyde azo dye and related Schiff bases. Journal of Molecular Liquids. 2013; 180: 225-234

11. Anitha C, Sheela C.D, Tharmaraj P, Sumathi S, Spectroscopic studies and biological evaluation of some transition metal complexes of azo Schiff-base ligand derived from (1-phenyl-2,3-dimethyl-4-aminopyrazol-5- 
one) and 5-((4-chlorophenyl)diazenyl)-2-hydroxybenzaldehyde. Spectrochimica Acta Part A: Molecular and Biomolecular Spectroscopy. 2012; 96: 493-500

12. Nazır H, Yıldız M, Yılmaz H, Tahir M.N, Ülkü D, Intramolecular hydrogen bonding and tautomerism in Schiff bases. Structure of $\mathrm{N}$-(2-pyridil)-2-oxo-1-naphthlidenemethylamine. Journal of Molecular Structure. 2000; 524: $241-250$

13. Pal M.K, Kushwah N, Wadawale AP, Manna D, Sudarsan V, Ghanty T.K, Jain V.K, Synthesis, characterization, photoluminescence and computational studies of mono- and diorgano-gallium complexes containing azo linked salicylaldimine Schiff bases. Journal of Organometallic Chemistry. 2015; 776: 98-106

14. Nagy P.I, Fabian W.M.F, Theoretical Study of the Enol Imine-Enaminone Tautomeric Equilibrium in Organic Solvents. J. Phys. Chem. B. 2006; 110: 25026-25032

15. Alaghaz A.M.A, Zayed M. E, Alharbi S. A, Synthesis, spectral characterization, molecular modeling and antimicrobial studies of tridentate azo-dye Schiff base metal complexes. Journal of Molecular Structure. 2015; 1084: $36-45$

16. Qian H.F, Tao T, Feng Y.N, Wang Y.G, Huang W, Crystal structures, solvatochromisms and DFT computations of three disperse azo dyes having the same azobenzene skeleton. Journal of Molecular Structure. 2016; 1123: 305-310

17. Atay Ç.K, Gökalp M, Kart S.Ö, Tilki T, Mono azo dyes derived from 5-nitroanthranilic acid: Synthesis, absorption properties and DFT calculations. Journal of Molecular Structure. 2017; 1141: 237-244.

18. Sreenath M.C, Mathew S, Joe H.I, Rastogi V.K, Z-scan measurements of the third-order optical nonlinearities and vibrational spectral studies by DFT computations on azo dye 1-(2-Methylphenylazo)-2napthol. Optics and Laser Technology. 2017; 97: 390-399.

19 Deshmukh M.S, Sekar N, A combined experimental and TD-DFT investigation of three disperse azo dyes having the nitroterephthalate skeleton. Dyes and Pigments. 2014; 103: 25-33

20. Turkten N, Cinar Z, Photocatalytic decolorization of azo dyes on TiO2: Prediction ofmechanism via conceptual DFT. Catalysis Today. 2017; 287: 169-175

21. Miraftab R, Ramezanzadeh B, Bahlakeh G, Mahdavian M, An advanced approach for fabricating a reduced graphene oxide-AZO dye/polyurethane composite with enhanced ultraviolet (UV) shielding. Chemical Engineering Journal. 2017; 321: 159-174

22. Erfantalab M, Khanmohammadi $H$, New 1,2,4-triazole-based azo-azomethine dye. Part III: Synthesis, characterization, thermal property, spectrophotometric and computational studies properties: Experimental and first-principles QM modeling. Spectrochimica Acta Part A: Molecular and Biomolecular Spectroscopy. 2014; 125: $345-352$

23. Gür M, Muğlu H, Çavus M.S, Güder A, Sayıner H.S, Kandemirli F, Synthesis, characterization, quantum chemical calculations and evaluation of antioxidant properties of 1,3,4-thiadiazole derivatives including 2- and 3-methoxy cinnamic acids. Journal of Molecular Structure. 2017; 1134: 40-50

24. Kohn W, Sham L.J, Self-consistent equations including exchange and correlation effects. Phys. Rev. 1965; 140: A1133.

25. Shahab S, Sheikhi M, Filippovich L, Kumar R, Dikusar E, Yahyaei H, et al. Synthesis, geometry optimization, spectroscopic investigations (UV/Vis, excited states, FT-IR) and application of new azomethine dyes. Journal of Molecular Structure. 2017 Nov;1148:134-49.

26. Endre J, Tibor Z., Antimicrobial, ascaricidal, and molluscicidal activities of salicylanilide analogs. Virusforschung und Parasitologie. 1967; 202 (4): 547-62

27. Gogotov, A. F., 4-Hydroxybenzylidenaniline and 4-hydroxyazobenzene derivatives as alternatives to nitrobenzene in the selective decomposition of lignin to vanillin. Russian Journal of Applied Chemistry 2000; 73(2): 324-29 
28. Gaussian 09, Revision B.01, Frisch M. J, Trucks G. W, Schlegel H. B, Scuseria G. E, Robb M. A, Cheeseman J. R, Scalmani G., Barone V, Mennucci B, Petersson G. A, Nakatsuji H, Caricato M, Li X, Hratchian H. P, Izmaylov A. F, Bloino J, Zheng G, Sonnenberg J. L, Hada M, Ehara M, Toyota K, Fukuda R, Hasegawa J, Ishida M, Nakajima T, Honda Y, Kitao O, Nakai H, Vreven T, Montgomery J. A, Peralta J. E, Ogliaro F, Bearpark M, Heyd J. J, Brothers E, Kudin K. N, Staroverov V. N, Keith T, Kobayashi R, Normand J, Raghavachari K, Rendell A, Burant J. C, Iyengar S. S, Tomasi J, Cossi M, Rega N, Millam J. M, Klene M, Knox J. E, Cross J. B, Bakken V, Adamo C, Jaramillo J, Gomperts R, Stratmann R. E, Yazyev O, Austin A. J, Cammi R, Pomelli C, Ochterski J. W, Martin R. L, Morokuma K, Zakrzewski V. G, Voth G. A, Salvador P, Dannenberg J. J, Dapprich S, Daniels A. D, Farkas O, Foresman J. B, Ortiz J. V, Cioslowski J, Fox D. J, Gaussian, Inc., Wallingford CT, 2010.

29.Becke $A D, A$ new mixing of HartreeeFock and local density-functional theories. J Chem Phys. 1993; 98:1372-7.

30. Lee C, Yang W, Parr RG. Development of the Colle-Salvetti correlation-energy formula into a functional of the electron density. Phys Rev B 1988; 37: 785-9.

31. Cossi M, Barone V, Cammi R, Tomasi J., Ab initio study of solvated molecules: a new implementation of the polarizable continuum model, Chem. Phys. Lett. 1996;255: 327-335. 
